\title{
Accelerated Hypofractionated Radiotherapy With Simultaneous Integrated Boost With Volumetric Modulated Arc Technique in Patients With Breast Cancer: a Phase 2 Study.
}

\section{Budhi Singh Yadav ( $\sim$ drbudhi@gmai.com )}

Post Graduate Institute of Medical Education and Research https://orcid.org/0000-0001-6185-4139

\section{Shipra Gupta}

NIC, Jhajjar, Haryana

Divya Dahiya

PGIMER: Post Graduate Institute of Medical Education and Research

\section{Ankita Gupta}

PGIMER: Post Graduate Institute of Medical Education and Research

\section{Arun Oinam}

PGIMER: Post Graduate Institute of Medical Education and Research

\section{Research Article}

Keywords: Breast cancer, accelerated hypofractionation, volumetric modulated arc technique

Posted Date: June 7th, 2021

DOl: https://doi.org/10.21203/rs.3.rs-542950/v1

License: (c) (1) This work is licensed under a Creative Commons Attribution 4.0 International License.

Read Full License 


\section{Abstract}

\section{Purpose}

To assess feasibility of accelerated hypofractionated radiotherapy with simultaneous integrated boost (SIB) with volumetric modulated arc technique (VMAT) in patients with breast cancer.

\section{Methods}

Total 27 patients after breast conserving surgery (BCS) were included in this study. Patients were planned on 4-dimensional computerized tomogram (4D-CT) and contouring was done using RTOG guidelines. Dose delivered was $34 \mathrm{~Gy} / 10 \# / 2 \mathrm{wk}$ to the breast and $40 \mathrm{~Gy} / 10 \# / 2 \mathrm{wk}$ to the tumor bed as SIB with VMAT technique. The primary endpoint was grade 2 acute skin toxicity. Doses to the organs at risk were calculated. Toxicities and cosmesis were assessed using RTOG LENT-SOMA and HARVARD/NSABP/RTOG grading scales, respectively. Disease-free survival (DFS) and overall survival (OS) was calculated with Kaplan Meier curves.

\section{Results}

Mean age of the patients was 42 years. Left and right breast cancer was seen in 17 (63\%) and 10 (37\%) patients, respectively. Ipsilateral lung mean V16 and contralateral lung V5 was $16.01 \%$ and $3.73 \%$, respectively. Mean heart dose from the left and right breast was 7.25Gy and 4.37Gy, respectively. Mean dose to the contralateral breast, oesophagus and spinal cord was 2.64Gy, 3.69Gy and 3.15Gy, respectively. Thyroid V25 mean was $19.69 \%$.

Grade 1 and 2 acute skin toxicity was observed in 9 (33\%) and 5 (18.5\%) patients, respectively. Grade 2 hyperpigmentation, edema and induration were observed in 1 (3.7\%), 2 (7.4\%) and 4(14.8\%) patients, respectively. Mild breast pain and arm/shoulder discomfort were reported by 1 (3.4\%) patient each. Median follow-up was 48 months (range 12-58 months). At 4 years breast induration, edema and fibrosis each were observed in 1(3.7\%) patient. Cosmesis was excellent and good in $21(78 \%)$ and $6(22 \%)$ patients, respectively. Local recurrence and distant metastases occurred $1(3.7 \%)$ and $2(7.4 \%)$ patients, respectively. DFS and OS at 3-years was $88 \%$ and $92 \%$, respectively.

\section{Conclusion}

With this RT schedule acute and late toxicity rates were acceptable with no adverse cosmesis. Local control, DFS and OS were good.

\section{Introduction}

Breast cancer is the most common cancer among women globally as well as in our country[1]. Radiotherapy (RT) plays an important role in breast cancer management after breast conserving surgery (BCS) or mastectomy. In patients with BCS, whole breast irradiation (WBI) can be delivered with many 
techniques. These techniques include 2-dimensional (2D), 3-dimensional conformal RT(3D-CRT) with or without deep inspiration breath hold, field-in-field intensity modulated RT(FF IMRT), inverse planning IMRT, tomotherapy, image guided RT(IGRT) and proton therapy. Many BCS patients may benefit from a boost to the primary site to prevent recurrences that occurs within $2 \mathrm{~cm}$ of the primary tumor location[2]. RT contributes by sterilizing the microscopic disease thus reducing the risk of local recurrence[3,4]. There are many techniques and modalities(photons, electrons and brachytherapy) by which boost can be delivered. The optimal modality, timing, dose fractionation and technique of tumor bed boost have not yet been established, especially with hypofractionated radiotherapy. However, for a patient who may benefit from boost, simultaneous integrated boost (SIB) can be one of the techniques for its delivery. It achieves dose conformity, homogeneity and completes the treatment fast in one plan only. If it is planned with volumetric-modulated arc therapy (VMAT), the treatment delivery is fast, and planning on 4D-CTcan improve its localization and onboard imaging can increase the accuracy of the delivery. Tumor bed boost has been shown to be associated with increased acute and late toxicity[5,6]. However, it depends on the total dose, dose per fraction, volume of the boost, modality and the technique used for boost delivery. In majority of the studies SIB was delivered in 3-5 weeks[7-11]. SIB with accelerated hypofractionation can further reduce treatment duration from 3 weeks to 2 weeks.

In this study, we report dosimetry, acute and late toxicities and the cosmetic outcomes in patients with breast cancer post BCS who were treated with accelerated hypofractionated WBI and SIB with VMAT technique over 2 weeks (10 fractions).

\section{Methods}

This prospective phase II study was conducted in the Department of Radiation Oncology, Regional Cancer Centre, XXXX, XXXX. Primary objective was to assess grade 2 acute skin toxicity with hypofractionated WBI with SIB completed in 10 fractions. Secondary objectives of the study were to determine dose distribution, target coverage, dose homogeneity dose conformity of the target volume, late toxicity and cosmetic outcomes.

\section{Patient selection}

Patients who had undergone BCS were included in this study. Institutional Ethics Committee approval was taken. Informed consent was taken from all the patients. The trial was registered with clinicaltrials.gov no. XXXX. Inclusion criteria were: primary cancer of breast of any histology, age $>18-70$ years, post BCS with clear margins, healed scar, Karnofsky performance status (KPS) $>70$, regional nodal radiation when indicated(depending on risk factors) and no distant metastasis. Neoadjuvant or adjuvant chemotherapy was allowed. Adjuvant endocrine therapy was given to patients with hormone receptor positive tumors. Exclusion criteria were: mastectomy, history of prior primary malignancy, prior irradiation to breast or chest, pregnancy and collagen vascular disease.

\section{Radiotherapy planning}


All patients were made to lie supine on a carbon fiber breast board or wing board or a $\mathrm{T}$ bar with ipsilateral arm abducted to $90^{\circ}$ and face turned to the opposite side. Radiopaque markers were placed for defining the superior, inferior, medial and lateral borders and the surgical scar. Three skin markings were placed along with the fiducials below the breast folds for the purpose of reproducibility and the location of tumor bed with respect to fiducials.

All patients underwent a normal free-breathing scan with virtual computerized tomogram (CT) breast simulation. Axial cuts were taken from the mandible to the upper abdomen with a slice thickness of 3 $\mathrm{mm}$. The 4D-CT images with recording of the respiratory signals were acquired, taking organ motion into account. The delineation of the tumor cavity and contouring of the OARs was done by using RTOG guidelines. Contouring for the target volumes were done on maximum intensity projection (MIP) of the 4D-CT. The OARs contoured were heart, bilateral lungs, contralateral breast, esophagus, spinal cord, left anterior descending artery and thyroid.

The affected breast was contoured as the clinical target volume (CTV) excluding $5 \mathrm{~mm}$ from the skin. An additional $5 \mathrm{~mm}(0.5 \mathrm{~cm})$ margin for setup error and motion was then added to CTV to form the planning target volume (PTV), shredding(removing) it from lungs and body by $5 \mathrm{~mm}$ to spare the skin. The nodal areas, when indicated according to the risk factors, were also contoured following RTOG contouring guidelines.

\section{Boost RT planning}

In each patient, tumor bed was delineated using clinical, radiological (mammography/CT/ultrasound of breast), surgical (intra operative notes, external and internal surgical scar location) findings, seroma cavity and surgical clips location. ITV was generated by contouring tumor bed in all phases of respiratory cycles on 4D-CT. All delineation was done on MIP images. A margin of $5 \mathrm{~mm}$ was added to the cavity to form PTV BOOST SIB. A dose of $34 \mathrm{~Gy} / 10 \# / 2 w k$ to the PTV TOTAL and $40 \mathrm{~Gy} / 10 \# / 2 w k$ to the PTV SIB BOOST was delivered with IGRT using the RapidArc $\circledast$ technique. Partial arcs were used for RT planning. Dose distribution and target coverage criteria for PTV TOTAL and PTV SIB BOOST were: $98 \%$ of volume should receive $>95 \%$ of dose and $2 \%$ volume should receive $<107 \%$ of dose. Conformity and homogeneity indices were also calculated for each plan[12-14].

Dose constraints given were; ipsilateral mean lung dose (MLD) $\leq 10 \mathrm{~Gy}, \mathrm{~V} 16 \mathrm{~Gy}<20 \%$ and contralateral lung V $5<5 \%$. Mean heart dose (MHD) $<7 G y$, V18 $<5 \%$ for left side and $<1 \%$ for the right side. LAD Dmax and Dmean $<15 G y$ and $<8$ Gy, respectively from left breast. Contralateral breast Dmean $<3 G y$. Thyroid V25 and V30 should be $<50 \%$ and $<25 \%$, respectively. Dmax and Dmean for oesophagus $20 \mathrm{~Gy}$ and $<5 \mathrm{~Gy}$, respectively. Dmax for the spinal cord and brachial plexus should be $<30 G y$ and $<40 G y$, respectively.

Cone beam CT was done on the first three consecutive days and then orthogonal images were taken daily for set-up verification. All patient were treated in free breathing.

\section{Assessments}


Toxicities: Baseline assessment was done for all the patients. The physicians examined patients for any toxicity every week during treatment, at the treatment completion and during the follow-up visits. First follow up was at 1 month of completion of. Patients were followed every 3 months in the 1 st year, every 4 months in the $2^{\text {nd }}$ year, every 6 months thereafter. Toxicities were scored according to Radiation Therapy Oncology Group (RTOG) and Late Effects on Normal Tissues (LENT)/Subjective, Objective, Management and Analytic (SOMA) grading scale. Acute toxicities are reported at 1 and 3 month of completion of radiotherapy. Late effects are reported at 6 months and 4 years follow up.

Cosmesis: Cosmetic effects were assessed in the treated breast and compared with the opposite breast and also with the baseline photographic evaluation. Both objective and subjective parameters were used. The Harvard/NSABP/RTOG scale proposed by Harris et al. was used to evaluate the cosmetic parameters[15]. Variability in both objective and subjective assessment was evaluated. Changes in terms of colour, shape, size, any swelling, symmetry, texture and position of nipple were noted in the treated breast. The assessment was done at baseline (before the start of radiation treatment), at the time of completion of treatment, at 1 month, 3 months, 6 months, 1 year and 3 years after completion of treatment. The long-term cosmetic effects were reported at 4 years. For subjective evaluation, a standard scale for assessment of cosmetic effect due to RT after BCS was used. For objective qualification, digital photography of the patient was used, before and after the treatment. Digital photo, in a front view of the patient including the sternal notch and both the breast with a light background with adequate light were taken. Two views with hands by side and hands raised above the head were taken for all the patients. A picture of the scar was also taken by the same person to avoid variability of clicked photos.

For cosmesis, both subjective (hyperpigmentation, change in shape, change in size, nipple changes, heaviness, pain) and objective (skin reaction, overall grade, edema, induration, subcutaneous fibrosis, tenderness, scar changes and any other skin changes/ulceration) response was considered. All the parameters were noticed for any change with time and graded upon accordingly.

Clinical Outcomes: Disease-free survival (DFS) and overall survival(OS) were summarized by KaplanMeier curves. Local recurrence was defined as recurrence in the in the involved breast, axilla, supraclavicular fossa and internal mammary nodes. Distant metastases were defined as disease occurring in the other sites. Local recurrence and distant metastases were used to calculate DFS. Time was calculated from the date of completion of RT. OS was defined from the date of diagnosis till the last follow-up or death due to breast cancer.

\section{Statistical analysis}

The purpose of the trial was to reject the experimental treatment from further study if it is too toxic, and to accept it for further study if the toxicity is acceptable. The primary endpoint was grade 2 acute skin toxicity, and other toxicities were considered secondary endpoints. The study was designed as a phase II trial with the following assumptions: 
- Grade 2 skin toxicity $\geq 36 \%$ was considered unacceptable, and grade 2 skin toxicity $\leq 11 \%$ was considered acceptable. Hence the hypotheses of interest were $H_{0}: r^{3} 36 \%$ against $H_{A}: r £ 11 \%$, where $r$ is the proportion of patients with grade 2 skin toxicity

- The type I error rate (a, probability of accepting an overly toxic treatment, a false positive outcome) was set to $5 \%$

- The type II error rate (b, probability of rejecting an acceptably toxic treatment, a false negative outcome) was set to $10 \%$ - i.e., the power is equal to $90 \%$

Under these assumptions, using a one-sided Fisher's exact test, the design consists of treating 27 evaluable patients, and

- if at most 5 patients have grade 2 skin toxicity, the treatment was considered acceptable $(5 / 27=19 \%)$

if at least 6 patients have grade 2 skin toxicity, the treatment was considered too toxic $(6 / 27=22 \%)$

\section{Results}

\section{Patient characteristics}

Between July 2016 to June 2017, 27 patients were treated. Mean age of the patients was 42 years (range 36-67 years). Left and right breast cancer was seen in 17 (63\%) and $10(37 \%)$ patients, respectively. The majority of patients were premenopausal $22(81 \%)$ and had T2 tumors $16(59 \%)$. Nodes were positive in $18(67 \%)$ patients (Table 1$)$. Axillary clearance was till level 3 in 25(92.5\%) patients and median number of dissected nodes were 19 . More than $50 \%$ of the patients had grade 3 disease and lymphovascular invasion. Supraclavicular fossa (SCF) was treated in 20 (74\%) patients. Internal mammary nodes were treated in one patient. Chemotherapy was given as neoadjuvant and adjuvant to $4(14.8 \%)$ and $22(81 \%)$ patients, respectively. Hormonal therapy was received by $18(67 \%)$ patients. Trastuzumab was received by $1(4 \%)$ patient only.

\section{Dosimetry}

Mean PTV and boost volume were $1099.8 \pm 512.9 \mathrm{cc}$ and $66.0 \pm 44.3 \mathrm{cc}$, respectively. The mean $\mathrm{Cl}$ for the PTV and boost was $0.90 \pm 0$ and $0.93 \pm 0.2$, respectively. $H$ for the PTV and boost was $0.31 \pm 0.1$ and $0.11 \pm 0.1$, respectively. Dmax to PTV boost was $43.2 \pm 1.5 \mathrm{~Gy}$. PTV and boost $\mathrm{V} 107 \%$ and $\mathrm{V} 105 \%$ were $2.97 \pm 8.81 \mathrm{cc}$ and $0.46 \pm 0.74 \mathrm{cc} ; 3.2 \pm 4.6 \mathrm{cc}$ and $0.66 \pm 0.82 \mathrm{cc}$, respectively.

Ipsilateral MLD was 9.86Gy(range 7.12Gy-13.72Gy). Ipsilateral lung mean V16 was $16.01 \%(2.12-27.42 \%)$ and contralateral lung mean V5 and V2 was 3.74\%(0.77-11.33\%) and 52.62\%(12.31-97.90\%), respectively. MLD with and without SCF radiotherapy was $10.08 \mathrm{~Gy}$ (range 7.13Gy-13.72Gy) $(\mathrm{n}=20)$ and $9.22 \mathrm{~Gy}$ (range 7.12Gy-11.50Gy) $(n=7)$, respectively. MHD was 7.25Gy(4.31Gy-10.85Gy) from the left breast and 4.37Gy(range 2.32Gy-7.13Gy) from the right breast. In patients with left breast cancer $(n=17)$, MHD with and without SCF treatment was 7.25Gy $(n=12)$ and 6.6Gy $(n=5)$, respectively. Mean V18 and V15 of the 
heart from the left and right breast was 2.88\%(0.05-8.98\%) and 0.30\%(0-1.69\%); and 6.20\%(0.22-18.26\%) and $1.1 \%(0-3.69 \%)$, respectively. Dmax to LAD from left breast was $14.24 \mathrm{~Gy}(8.9-27.86 \mathrm{~Gy})$. Mean LAD dose from the left and right breast was 7.74Gy(4.42-21.26Gy) and 3.32Gy(1.41-6.72Gy), respectively. Mean dose to the contralateral breast, oesophagus and spinal cord was 2.64Gy $(1.53-4.16 \mathrm{~Gy})$, 3.69Gy(1.55-9.02Gy) and 3.15Gy(0.84-18.65Gy), respectively. Dmax to the oesophagus was $15.65 \mathrm{~Gy}(4.48-32.8 \mathrm{~Gy})$. Mean of Dmax to spinal cord and brachial plexus was $10.43 \mathrm{~Gy}(2.32-28.40 \mathrm{~Gy})$ and $26.95 \mathrm{~Gy}(6.72-38.42 \mathrm{~Gy})$, respectively. Thyroid V25 and V30 mean were $19.69 \%$ (range $0-52.97 \%$ ) and $11.83 \%$ (range $0-36.90 \%$ ), respectively (Table 2 ).

Dose constraints for MLD $\leq 10 \mathrm{~Gy}$, ipsilateral lung V16 < 20\% and contralateral lung V $5<5 \%$ were achieved in $70.37 \%, 81.48 \%$ and $92.59 \%$ of patients, respectively (Table 2). MHD from left breast cancer $<8$ Gy was achieved in $94.11 \%$ patients. Heart V18 $<5 \%$ for left side and $<1 \%$ for the right side were achieved in $88.24 \%$ and $90 \%$ of patients, respectively. LAD Dmax $(<15 \mathrm{~Gy}$ ) for left breast was achieved in $82.35 \%$ patients. LAD Dmax <8Gy from left breast and <5Gy from right breast were achieved in $88.24 \%$ and $80 \%$ of patients, respectively. Contralateral breast Dmean $<3 \mathrm{~Gy}$ ) was achieved in $77.78 \%$ of patients. Thyroid V25 and $\mathrm{V} 30<25 \%$ and $<50 \%$, respectively were achieved in $70.27 \%$ and $88.89 \%$ of patients, respectively. Oesophagus Dmax ( $<18 \mathrm{~Gy}$ ) and Dmean ( $<5 \mathrm{~Gy}$ ) were achieved and $85.19 \%$ and $70.03 \%$ of patients, respectively. Average of Dmax was higher in patients who received SCF radiation(18.66Gy) as compared to those who did not(7.0Gy). Spinal cord Dmean ( $<5 \mathrm{~Gy}$ ) and Dmax (<30Gy) were achieved in $88.89 \%$ and $100 \%$ patients, respectively.

There was significant dose reduction to the thyroid with head position and whether SCF was treated or not(Table 3). Mean thyroid dose in patients with and without head rotation was $11.00 \mathrm{~Gy}(95 \% \mathrm{Cl} 6.67-$ $15.32)$ and $22.68 \mathrm{~Gy}(95 \% \mathrm{Cl} 20.00-25.36)$, respectively $(\mathrm{p}<0.0001)$. Similarly, mean thyroid dose with and without SCF treatment was $16.95 \mathrm{~Gy}(95 \% \mathrm{Cl} 13.08-20.82)$ and $0.67 \mathrm{~Gy}(95 \% \mathrm{Cl} 0.34-0.99)$, respectively $(p<0.0001)$.

\section{Acute Toxicity}

Grade 1 and 2 acute skin toxicity was observed in 9 (33\%) and 5 (18.5\%) patients, respectively(Table 4). Acute grade 2 skin toxicity in patients with and without nodal radiotherapy was $1(14.2 \%)$ and $4(20 \%)$, respectively. There was no grade 3 acute skin toxicity. This rate of grade 2 acute skin toxicity met the predefined criteria of $\leq 5 / 27$ for acceptable toxicity.

All of the secondary toxicities at 1 month also met the predefined criteria for acceptable toxicity. Grade 2 hyperpigmentation, edema and induration were observed in 1 (3.7\%), 2 (7\%) and 4(14.8\%) patients, respectively. At 1 month, patient reported acute toxicities were mild swelling, heaviness and pain in $1(3.7 \%), 4(14.8 \%)$ and $8(29 \%)$ patients, respectively. Mild difficulty in swallowing was reported by $1(3.7 \%)$ patient in whom internal mammary nodes were also treated. None of the patients developed acute radiation pneumonitis. Dmax to the oesophagus in this patient was 32.8Gy.

\section{Late toxicity}


Late toxicities were either grade 1 or 2(Table 5). In comparison to the baseline, toxicities increased till 6 months then decreased after that. Late grade 1 and grade 2 breast induration at 4 years was observed in $4(14.8 \%)$ and $1(3.7 \%)$ patient, respectively. These were present at baseline also. Breast edema was seen in $2(7.4 \%)$ patients at baseline, which reduced at 4 years to $1(3.7 \%)$ only. Grade 1 breast fibrosis was observed in $1(3.7 \%)$ patient at 4 years. Grade 1 arm edema was seen in 2(7.4\%) patients at baseline, which persisted in $1(3.7 \%)$ patient till $4^{\text {th }}$ year.

Patient reported outcomes were mild to moderate only. At baseline mild to moderate breast pain was reported by $2(7.4 \%)$ patients, which became mild at 4 years. Breast heaviness was reported by $2(7.4 \%)$ patients at baseline, which persisted till $4^{\text {th }}$ year. Mild breast shrinkage was reported by $1(3.7 \%)$ and 2(7.4\%) patients at baseline and 4 years, respectively. Mild arm/shoulder discomfort was reported by $1(3.7 \%)$ patient only. Arm swelling at 4 years was reported by only $1(3.7 \%)$ patient. There were no grade 3 late toxicities. There was no brachial plexopathy or rib fracture with this schedule. We did not observe any late cardiac or pulmonary toxicity(Table 5).

\section{Cosmesis}

Physician/patient observed cosmesis was excellent and good in $21(78 \%) / 19(70 \%)$ and $6(22 \%) / 8(30 \%)$ patients, respectively(Figures 1 and 2). None of the patients had adverse cosmesis. None of the parameters such as $\mathrm{V} 107 \%$, V105\%, breast size and boost volume were related with late effects or cosmesis.

\section{Outcomes}

At a median follow-up of 48 months (range 12-58 months), local recurrence occurred in 1 (3.7\%) patient. Distant metastases were seen in $2(7.4 \%)$ patients. DFS and OS at 4 years was $88 \%(95 \% \mathrm{Cl} 77 \%-100 \%)$ and $92 \%(95 \% \mathrm{Cl} 82 \%-100 \%)$, respectively.

\section{Discussion}

In this study we reported the doses to the target organ, the OARs, acute and late toxicities and the cosmesis in breast cancer patients post BCS who were treated with accelerated hypofractionated locoregional RT schedule of $34 \mathrm{~Gy} / 10 \# / 2$ week (3.4Gy/fraction) to the whole breast and $40 \mathrm{~Gy}$ (4Gy/fraction) to the tumor area with SIB with VMAT technique in 12 days. Dose constraints were achieved in the majority of patients with low rates of acute and late toxicities. There was no adverse cosmesis. Local control and survival were good with this schedule. Since grade 2 skin toxicity occurred in 5 (18.5\%) patients, this treatment is acceptable according to the assumption in null hypothesis for this study.

WBI dose fractionation has changed over the years. We modified dosimetric constraints for the lung to V16 and heart to V18, which would be biologically equivalent to V20 and V25 of the conventional schedule, respectively. MHD dose in the current study was 7.25Gy, which may be because of the partial arcs, which were used for planning. This MHD may not be acceptable currently because of the risk of late- 
term cardiac complications. In a study by Darby et al. they reported that the rate of major coronary events increased by $7.4 \%$ for each 1 Gy increase in MHD. They also demonstrated a threshold MHD of 3 Gy, implying an attributable absolute increased cardiac mortality of 0.5 to $0.7 \%$ for women $<50$ years depending on number of cardiac risk factors. As per their observations MHD was a better predictor of coronary events than the mean LAD dose and these events started within 5-years of treatment[16]. However, their study was from 2D era based on average anatomy and lacked individual dosimetric information hence its ramifications remains unresolved. Recently we published our results at 5-year with this schedule with 2D technique. We did not encounter excess late arm/shoulder and cardiac toxicity, although 5-year may not be adequate to report cardiac toxicities[17]. MHD of 7.25Gy in the current study is higher so there might be a risk of coronary events in the future. Earlier studies have also reported that VMAT increases MLD, MHD and dose to the opposite breast[18]. Considering this risk 3D-CRT with deep inspiration breath hold, inverse planned fixed field IMRT, treatment in prone position, hybrid techniques of combining tangential IMRT with VMAT and proton therapy may be more appropriate in achieving lower MHD and doses to other OARs[19-21]. IMRT has been shown to improve target coverage and reduce dose to the OARs[19]. Taylor et al. in another population-based study calculated the absolute risk of mortality from lung cancer at 5Gy MLD and ischemic heart disease at 4Gy MHD after breast RT for smokers and non-smokers to be $0.3 \%$ and $4.4 \%$; and $0.3 \%$ and $1.2 \%$, respectively. However, these doses were estimated retrospectively[22]. In a recent study Merzenich et al. reported that average MHD of 4.6Gy for left-sided breast RT and only pre-exiting cardiac disease was associated with risk of cardiac death[23]. While another study reported V25 and V30 to be detrimental to the heart[24].

In our previous study with 3D-CRT in patients with left-sided breast cancer postmastectomy; MHD, LAD, proximal LAD, and distal LAD doses were 3.364 Gy, $16.06 \mathrm{~Gy}, 2.7 \mathrm{~Gy}$, and 27.5 Gy, respectively. Left MLD, V10, and V20 were $5.96 \mathrm{~Gy}, 14 \%$, and $12.4 \%$, respectively. Mean dose to the right lung and the opposite breast was $0.29 \mathrm{~Gy}$ and $0.54 \mathrm{~Gy}$, respectively. V25 for heart was 4.25\%[25]. In another study with 3D-CRT in left-sided patients with BCS; MHD in the supine and prone positions was $4.55 \mathrm{~Gy}$ and $2.06 \mathrm{~Gy}(\mathrm{p}=$ $0.02)$, respectively. MLD in the supine and prone positions was $6.58 \mathrm{~Gy}$ and $0.85 \mathrm{~Gy}(\mathrm{p}=0.001)$, respectively[26]. All these doses are quite low as compared to the current study. DIBH reduces cardiac volume in the RT field, hence it lead to reduction in all dose parameters(mean, maximum and volume based) of the heart[27,28]. It has been shown to reduce cardiac mortality by $4.7 \%$ compared to free breathing with median cardiac mortality normal tissue complication probability of $0.1 \%$ in patients leftsided breast cancer[29]. Because of changes in dose fractionation (from conventional to hypofractionation) and techniques of RT for breast cancer(from 2D to 3D-CRT/FIF IMRT), it still remains unclear what dose constraints to be placed for heart, LAD and lungs; and how is it going affect the cardiac related mortality? Although MHD has been the gold standard for prediction of late cardiac effects in the past studies but recent studies have suggested that reporting doses to the heart substructures such as apical part of left ventricle and LAD may be of relevance[30,31] Hypofractionation may result in lower equivalent doses (EQD2) to the heart as compared to conventional fractionation and comparable late effects[32,33]. However, till data comes clear on these aspects, patients with left-sided breast cancer should be offered techniques, which reduces dose to the heart and lungs. 
Second cancers after breast radiation are also a possibility with VMAT because of low dose to larger volume of OARs. In the present study $50 \%$ of the contralateral lung received $2 \mathrm{~Gy}$, so it may put this OAR for second cancer. Hall et al. in their study estimated $1 \%$ to $1.75 \%$ increase in the incidence of second cancers after 3D-CRT and IMRT at 10 years[34]. VMAT technique was also reported to increase this risk in one study[19] where as it was comparable in another for the contralateral breast and lung, but less risk in the ipsilateral lung because of reduced MLD with VMAT[35]. In a recent review, it was observed that VMAT increases contralateral lung V 5 by $25 \%$ as compared to other techniques[36]. In our study contralateral lung V 5 of $3.74 \%$ is still lower as compared to other studies. This reduction in V 5 is associated with reduction in secondary cancer[35,36] Since, ipsilateral MLD, contralateral lung V 5 and breast mean doses in our study are comparable to those observed by Zhang et al., we may expect similar risk of second cancers in our patients. However, this risk may vary with distance of the organ from the sternum, patient anatomy, dose optimization, set up errors, organ motion[37] and smoking[22]. In our past series we have reported second cancers in the contralateral breast, oesophagus and lung cancers in $3.3 \%, 0.22 \%$ and $0.05 \%$ patients, respectively[25].

Many dosimetric studies have explored the potential benefits of integrating boost with WBI, but the majority of them are with conventional fractionation[38-42]. There are few studies where boost has been integrated with moderate hypofractionation and treatment completed in 3-4 weeks[7-11, 43-45]. and 5-6 weeks in others[47,50]. A multicentric study of 151 patients by Dellas et al. from Germany with RT dose of 40Gy in 16 fractions for WBI and a SIB with $0.5 \mathrm{~Gy} /$ fraction to the primary area, reported that dose constraints could be achieved and SIB was feasible with hypofractionation[42].

In the present study we integrated boost with accelerated hypofractionation and completed treatment in 2 weeks only. With changes in hypofractionation schedules in breast cancer we have to look for OARs constraints, which can be achieved with a particular dose fractionation schedule. In our study we achieved dose constraints to the OARs such as lungs, heart(high dose volume), contralateral breast and oesophagus in $>80 \%$ of patients, except for the MLD, MHD, mean dose to contralateral breast ( $<3 \mathrm{~Gy}$ ) and V30 ( $<25 \%)$ to the thyroid that could be achieved in $70 \%, 59 \%, 77 \%$ and $70 \%$ of patients, respectively (Table 2). MLD was slightly higher with SCF treatment (10.08Gy vs $9.22 \mathrm{~Gy}$ ). There was no impact of SCF treatment on the MHD. One of the observations of our study was that dose to the thyroid could be reduced significantly with head rotation. Dose to the thyroid was $7.84 \mathrm{~Gy}$ and $34.73 \mathrm{~Gy}(\mathrm{p}<0.0001)$ with and without head rotation, respectively (Table 3).

De Rose et al. reported a phase II trial of hypofractionated RT with VMAT in 787 patients with early breast cancer with a dose of 40.5Gy to whole breast and 48Gy to the tumor bed in 15 fractions over 3 weeks with VMAT. Grade 1 and 2 acute toxicity was observed in only $51 \%$ and $9.7 \%$ patients, respectively. At a median follow-up of 45 months, grade 1 toxicity was $13.5 \%$ and 4 patients had distant relapse. Cosmetic outcomes were excellent/good in 100\% patients[8]. In our study, grade 1 acute toxicity was less than those reported by De Rose et al., perhaps because of the lower total dose used in our study. We also observed only one local recurrence and two distant metastases at a median follow-up of 48 months. Both patients with distant metastases had triple negative disease. Our results are quite consistent with the 
studies published in the literature (Table 6) in terms of acute toxicity, cosmetic outcomes, local control, DFS and OS. Acute grade 2 toxicity in these studies ranged from $4 \%-43 \%$, and upper limit of $95 \% \mathrm{Cl}$ of our study $35 \%$, lie well within this range. Higher grade 2 toxicity in the study by Freedman et al. could be because of delivery of higher total dose (56Gy)[9]. However, local control was comparable to our study. We did not observe any late grade 3 toxicities. At 4-years, loco-regional control and excellent/good cosmesis of $96.5 \%$ and $100 \%$ in our study are also comparable to those reported in literature $(97 \%-100 \%)$ and (77\%-100\%), respectively (Table 6). Joppe et al. reported cosmetic outcomes with $8.5 \%$ grade 2 fibrosis in the boost area, chest wall pain in $6.7 \%$ patients, and telangiectasia grade $\geq 2$ in $3.7 \%$ patients at a median follow-up of 30 months. All-grade fibrosis outside the tumor bed was observed in $50 \%$ of patients. Higher fibrosis, chest wall pain and telangiectasia rate could be because of a high total dose delivered (64.4-67.2 Gy) in their study[47-50]. We did not observe any telangiectasia or chest wall pain in our study. So the present schedule may be better in terms of toxicities and cosmetic outcomes. In our study the treatment was completed in 12 days only with a similar toxicity profile, cosmetic outcomes and comparable local control, DFS and OS.

There are a few limitations to our study. The number of patients enrolled was less, because of the study design. Median follow-up of 48 months is modest; therefore; late toxicities and prolonged clinical outcomes need to be further assessed since we have delivered accelerated hypofractionation regimen with a dose of $3.4 \mathrm{~Gy} /$ fraction to the breast and $4 \mathrm{~Gy} /$ fraction to the tumor bed which may lead to late radiobiological consequences, although the likely risk is less because of the total delivered dose (40Gy) with one of the optimal techniques of RT. Low doses to lungs and contralateral breast may also not favor VMAT implementation but these can be further reduced by using tangential VMAT or hybrid VMAT. Lastly, it is an expensive technique and one of ASTRO Choosing Wisely Campaign initiatives is "Don't routinely use IMRT to deliver whole breast radiotherapy as part of breast conservation therapy"[51].

This study has shown comparable results with the previous studies(Table 6). Since the higher dose per fraction was used, the overall treatment time was reduced to only 12 days. It helped in increasing treatment compliance of the patients because of less acute toxicity. It also helped in reducing cost to the patient with increased convenience by reducing the number of hospital visits and has potential to reduce risk of local recurrence with acceptable toxicities in the breast because of its low $\alpha / \beta$ ratio. Therefore, the implication of this study is, reduction of total treatment time from 4 weeks to 2 weeks and reduction in the waiting time for the other patients.

To conclude, this study demonstrated that accelerated hypofractionated radiotherapy with SIB boost is feasible and safe in terms of acute and late breast toxicities. Radiation induced heart disease and stochastic effects might be a concern with higher MHD and low dose bath with this technique. VMAT plans may be used when conformal techniques are not able to achieve the desired dosimetric constraints. A phase III randomized controlled trial with same fractionation schedule with 2D/3D-CRT and DIBH techniques (XXXX; NCT XXXX) is on going and has completed patient accrual.

\section{Declarations}




\section{Funding: NA}

Conflicts of interest/Competing interests : none

Availability of data and material: data will be made available through suitable request

Code availability: N/A

Authors' contributions:

Research Methodology: BSY, SG, DD

Planning and treatment: BSY, SG, AG, AOS

Patient contribution: DD

Analysis: BSY, SG, AG

Manuscript writing: BSY, SG

Approval: All the authors

Ethics approval: Taken (include appropriate approvals or waivers)

Consent to participate: informed consent taken from all the patients

Consent for publication: Taken

\section{References}

1. Bray F, Ferlay J, Sorejomatram I et al. Global cancer statistics 2018: GLOBOCAN estimates of incidence and mortality worldwide for 36 cancers in 185 countries. CA 2018

2. Freedman GM, Anderson PR, Hanlon AL et al (2005) Pattern of local recurrence after conservative surgery and whole-breast irradiation. Int J Radiat Oncol Biol Phys 61:1328-1336

3. Polgár C, Jánváry L, Major T, Somogyi A, Takácsi-Nagy Z, Fröhlich G et al. The role of high-dose-rate brachytherapy boost in breast-conserving therapy: Long-term results of the Hungarian National Institute of Oncology. Reports Pract Oncol Radiother J Gt Cancer Cent Pozn Polish Soc Radiat Oncol. 2010 [;15(1):1-7

4. Romestaing P, Lehingue $Y$, Carrie C, Coquard R, Montbarbon X, Ardiet JM et al (1997 Mar) Role of a 10-Gy boost in the conservative treatment of early breast cancer: results of a randomized clinical trial in Lyon, France. J Clin Oncol 15(3):963-968

5. Bartelink H, Horiot J-C, Poortmans $P$ et al (2007) Impact of higher radiation dose on local control, survival in breast conserving therapy of early breast cancer: 10 years results of the randomized boost versus no boost EORTC trial 22881-10882. J ClinOncol 25:3259-3265 


\section{6. $X X X X$}

7. Franco P, Zeverino M, Migliaccio F et al (2013) Intensity-modulated adjuvant whole breast radiation delivered with static angle tomotherapy (TomoDirect): a prospective case series. J Cancer Res Clin Oncol 139:1927-1936

8. De Rose F, Fogliata A, Franceschini D, Navarria P, Villa E, Iftode C et al. Phase II trial of hypofractionated VMAT-based treatment for early stage breast cancer: 2-year toxicity and clinical results. Radiat Oncol. 2016 Dec 17;11(1):120

9. Freedman GM, Anderson PR, Goldstein LJ, Ma C-M, Li J, Swaby RF et al (2007) Four-Week Course of Radiation for Breast Cancer Using Hypofractionated Intensity Modulated Radiation Therapy With an Incorporated Boost. Int J Radiat Oncol]. Jun 1;68(2):347-53

10. Chadha M, Woode R, Sillanpaa J et al (2013) Early-stage breast cancer treated with 3-week accelerated whole-breast radiation therapy and concomitant boost. Int $\mathrm{J}$ Radiat Oncol Biol Phys 86:40-44

11. Formenti SC, Gidea-Addeo D, Goldberg JD, Roses DF, Guth A, Rosenstein BS et al (2007) Phase I-II Trial of Prone Accelerated Intensity Modulated Radiation Therapy to the Breast to Optimally Spare Normal Tissue. J Clin Oncol Jun [;25(16):2236-2242

12. Feuvret L, Noel G, Mazeron, Jean-JacquesB, Pierre. Conformity index: A review. Int J Radiat Oncol Biol Phys. 2006 Feb 1; 64(2): 333-42

13. Gong Y, Wang J, Bai S, Jiang X, Xu F (2008) Conventionally-fractionated image-guided intensity modulated radiotherapy (IG-IMRT): A safe and effective treatment for cancer spinal metastasis. Radiat oncol 3:11. [PMC free article] [PubMed] [Google Scholar]

14. Wu Q, Mohan R, Morris M, Lavue A, Schmidt-Ullrich R (2003) Simultaneous integrated boost intensity-modulated radiotherapy for locally advanced head-and-neck squamous cell carcinomas: Dosimetric results. Int J Radiat Oncol Biol Phys 26:573-585

15. Harris JR, Levene MB, Svensson G, Hellman S (1979) Analysis of cosmetic results following primary radiation therapy for stages I and II carcinoma of the breast. Int J Radiat Oncol. Feb 1;5(2):257-61

16. Darby SC, Ewertz M, McGale P, Bennet AM, Blom-Goldman U, Bronnum D (2013) Risk of ischemic heart disease in women after radiotherapy for breast cancer. N Engl J Med 368:987-998. [PubMed] [Google Scholar] [Ref list]

17. $x x x x$

18. Jin G-H, Chen L-X, Deng X-W, Liu XW, Huang Y, Huang XB (2013) A comparative dosimetric study for treating left-sided breast cancer for small breast size using five different radiotherapy techniques: conventional tangential field, filed-in-filed, Tangential-IMRT, Multi-beam IMRT and VMAT. Radiat Oncol 8:89

19. Hurkmans CW, Cho BCJ, Damen E, Zijp L, Mijnheer BJ (2002) Reduction of cardiac and lung complication probabilities after breast irradiation using conformal radiotherapy with or without intensity modulation. Radiother Oncol 62:163-171 
20. Krengli M, Masini L, Caltavuturo T, Pisani C, Apicella G, Negri E et al (2013) Prone versus supine position for adjuvant breast radiotherapy: a prospective study in patients with pendulous breasts. Radiat Oncol 8:232

21. Mast ME, Van Kempen-Harteveld L, Heijenbrok MW, Kalidien Y, Rozema H, Jansen WP et al (2013) Left-sided breast cancer radiotherapy with and without breath-hold: Does IMRT reduce the cardiac dose even further? Radiother Oncol 108:248-253

22. Taylor C, Correa C, Duane FK et al. Estimating the Risks of Breast Cancer Radiotherapy: Evidence From Modern Radiation Doses to the Lungs and Heart and From Previous Randomized Trials. JCO 2017;35(15):1641-51

23. Merzenich H, Bartkowiak D, Schmidberger H, Schmidt M, Schwentner L, Wiegel T (2017) 3D conformal radiotherapy is not associated with the long-term cardiac mortality in breast cancer patients: a retrospective cohort study in Germany (PASSOS-Heart Study. Breast Cancer Res Treat 161:143-152. [PubMed] [Google Scholar] [Ref list]

24. Gagliardi G, Constine LS, Moiseenko V, Correa C, Pierce LJ, Allen AM et al (2010) Radiation dosevolume effects in the heart. Int J Radiat Oncol Biol Phys 76:S77-S85

25. $X X X X$

26. $X X X X$

27. Nemoto K, Oguchi M, Nakajima M et al (2009) Cardiac-sparing radiotherapy for the left breast cancer with deep breath-holding. Jpn J Radiol 27:259-263

28. Nissen HD, Appelt AL. Improved heart, lung, and target dose with deep inspiration breath hold in a large clinical series of breast cancer patients. Radiother Oncol 2013:28-32

29. Korreman SS, Pederson AN, Aarup LR et al (2006) Reduction of cardiac and pulmonary complication probabilities after breathing adapted radiotherapy for breast cancer. Int J Radiat Oncol Biol Phys 65:1375-1380

30. Munshi A, Khataniar N, Sarkar B et al. Spatial orientation of coronary arteries and its implication for breast and thoracic radiotherapy-proposing "coronary strip" as a new organ at risk. Strahlenther Onkol. 2018 [PubMed] [Google Scholar]

31. Piroth MD, Petz D, Pinkawa M et al (2016) Usefulness of a thermoplastic breast bra for breast cancer radiotherapy: a prospective analysis. Strahlenther Onkol 192(9):609-616 doi: 10.1007/s00066-0160981-0. [PubMed] [CrossRef] [Google Scholar]

32. Appelt AL, Vogelius IR, Bentzen SM (2013) Modern hypofractionation schedules for tangential whole breast irradiation decrease the fraction size-corrected dose to the heart. Clin Oncol ( $r$ Coll Radiol) 25(3):147-152. doi:10.1016/j.clon.2012.07.012

33. James M, Swadi S, Yi M et al (2018) Ischaemic heart disease following conventional and hypofractionated radiation treatment in a contemporary breast cancer series. J Med Imaging Radiat Oncol 62(3):425-431. doi:10.1111/1754-9485.12712

34. Hall EJ, Wuu C-S (2003) Radiation-induced second cancers: the impact of 3D-CRT and IMRT. Int J Radiat Oncol Biol Phys 56:83-88 
35. Abo-Madyan Y, Aziz MH, Aly MM, Schneider F, Sperk E, Clausen S et al (2014) Second cancer risk after 3D-CRT, IMRT and VMAT for breast cancer. Radiother Oncol 110:471-476

36. Ashby $O$, Bridge $P$ (2021) Late effects arising from volumetric modulated arc therapy to the breast: $A$ systematic review. Radiography 27:650e653

37. Zhang Q, Liu J, Ao N, Yu H, Peng Y, Ou L, Zhang S. Secondary cancer risk after radiation therapy for breast cancer with different radiotherapy techniques. Sci Rep. 2020 Jan 27;10(1):1220. doi: 10.1038/s41598-020-58134-z.PMID: 31988348

38. Rose MA, Olivotto I, Cady B, Koufman C, Osteen R, Silver B et al (1989) Conservative surgery and radiation therapy for early breast cancer. Long-term cosmetic result. Arch Surg 124:153-157

39. Singla R, King S, Abuquerque K et al (2006) Simultaneous integrated boost intensity-modulated radiation therapy (SIB-IMRT) in the treatment of early-stage left-sided breast carcinoma. Med Dosim 31:190-196

40. Hurkmans CW, Meijer GJ, van-Vliet-Vroegindeweij et al (2006) High-dose simultaneously integrated breast boost using intensity-modulated radiotherapy and inverse optimization. Int J Radiat Oncol Biol Phys 66:923-930

41. Van der Laan HP, Dolsma WV, Maduro JH et al (2007) Three dimensional conformal simultaneously integrated boost technique for breast-conserving radiotherapy. Int J Radiat Oncol Biol Phys 68:10181023

42. Hijal T, Fourniez-Bodoz N, Castro-Pena P et al (2010) Simultaneous integrated boost in breast conserving treatment of the breast: a dosimetric comparison of helical and three-dimensional conformal radiotherapy. Radiother Oncol 94:300-306

43. Dellas K, Vonthein R, Zimmer J, Dinges S, Boicev AD, Andreas P et al (2014 Jul) Hypofractionation with simultaneous integrated boost for early breast cancer. Strahlentherapie Onkol 16(7):646-653 190(

44. Krug D, Baumann R, Krockenberger K et al (2020) Adjuvant hypofractionated radiotherapy with simultaneous integrated boost after breast-conserving surgery: results of a prospective trial. Strahlenther Onkol. https://doi.org/10.1007/s00066-020-01689-7

45. Cante D, Rosa La Porta M, Casanova-Borca V et al (2011) Accelerated hypofractionated adjuvant whole breast radiotherapy with concomitant photon boost after conserving surgery for early breast cancer: a prospective evaluation on 463 patients. Breast J 17:586-593. [PubMed] [Google Scholar]

46. Cante D, Franco P, Sciacero P et al (2013) Five-year results of a prospective case series of accelerated hypofractionated whole breast radiation with concomitant boost to the tumor bed after conserving surgery for early breast cancer. Med Oncol 30:518. [PubMed] [Google Scholar]

47. Bantema-Joppe EJ, Vredeveld EJ, deBock GH et al (2013) Five year outcome of hypofractionated simultaneous integrated boost irradiation in breast conserving therapy: patterns of recurrence. Radiother Oncol 108:269-272. [PubMed] [Google Scholar]

48. Bantema-Joppe EJ, Schilstra C, de Bock GH et al (2012) Simultaneous integrated boost irradiation after breast-conserving surgery: physician-rated toxicity and cosmetic outcome at 30 months' follow 
up. Int J Radiat Oncol Biol Phys 83:e471-e477. [PubMed] [Google Scholar]

49. Bantema-Joppe EJ, Schilstra C, de Bock GH et al (2012) Simultaneous integrated boost irradiation after breast conserving surgery: physician-rated toxicity and cosmetic outcome at 30 months' follow up. Int J Radiat Oncol Biol Phys 83:e471-e477

50. McDonald MW, Godette KD, Whitaker DJ et al (2010) Three-year outcomes of breast intensitymodulated radiation therapy with simultaneous integrated boost. Int J Radiat Oncol Biol Phys 77:523-530

51. ASTRO - IMRT for whole breast radiotherapy | Choosing Wisely

\section{Tables}

Table 1. Patient characteristics 


\begin{tabular}{|c|c|}
\hline Characteristics & $\mathrm{N}(\%)$ \\
\hline \multicolumn{2}{|l|}{ Comorbidities } \\
\hline Yes & $9(33)$ \\
\hline No & $18(67)$ \\
\hline \multicolumn{2}{|c|}{ Menopausal status } \\
\hline Premenopausal & $22(81)$ \\
\hline Postmenopausal & $5(19)$ \\
\hline \multicolumn{2}{|c|}{ Clinical Tumor stage } \\
\hline $\mathrm{T} 1$ & $9(33)$ \\
\hline T2 & $16(59)$ \\
\hline T3 & $2(4)$ \\
\hline \multicolumn{2}{|l|}{ pTumor stage } \\
\hline T1 & $10(37)$ \\
\hline T2 & $16(59)$ \\
\hline T3 & $1(4)$ \\
\hline \multicolumn{2}{|l|}{ pNodal stage } \\
\hline No & $9(33)$ \\
\hline N1 & $11(41)$ \\
\hline N2 & $6(22)$ \\
\hline N3 & $1(4)$ \\
\hline \multicolumn{2}{|l|}{ Grade } \\
\hline $1 \& 2$ & $13(48)$ \\
\hline 3 & $14(52)$ \\
\hline \multicolumn{2}{|c|}{ Lymphovascular invasion } \\
\hline Yes & $15(56)$ \\
\hline No & $12(44)$ \\
\hline \multicolumn{2}{|l|}{ DCIS } \\
\hline Present & $8(30)$ \\
\hline Absent & 19(70) \\
\hline
\end{tabular}

Page 17/24 


\begin{tabular}{|ll|} 
Positive & $15(56)$ \\
Pegative & $12(44)$ \\
Positive & \\
Negative & $13(48)$ \\
Her2neu & $14(52)$ \\
Positive & \\
Negative & $8(30)$ \\
\hline Ki67 & $19(70)$ \\
$\leq 14$ & \\
$>14$ & $5(19)$ \\
\hline Chemotherapy & $22(81)$ \\
Yes & \\
No & $26(96)$ \\
\hline Hormones & $1(4)$ \\
Yes & \\
No & $18(67)$ \\
\hline Trastuzumab & $9(33)$ \\
Yes & \\
No & $1(4)$ \\
\hline
\end{tabular}

Table 2. Doses to the organs at risk and constraints achieved $(\mathrm{n} / \mathrm{N})$ 


\begin{tabular}{|llllll|}
\hline & Dose & & & \multicolumn{2}{l}{ Constraint achieved } \\
\cline { 6 - 7 } Organ at risk & constraint & $\mathrm{N}$ & Mean $\pm \mathrm{SD}$ & $\mathrm{n}$ & $\%$ \\
\hline Mean lung dose & $\leq 10 \mathrm{~Gy}$ & 27 & $9.86 \pm 1.86$ & 19 & 70.37 \\
\hline Ipsilateral lung V20Gy & $\leq 10 \%$ & 27 & $8.88 \pm 4.29$ & 21 & 77.78 \\
\hline Ipsilateral lung V16Gy & $<20 \%$ & 27 & $16.01 \pm 4.29$ & 22 & 81.48 \\
\hline Ipsilateral lung V10Gy & - & 27 & $39.60 \pm 14.21$ & - & - \\
\hline Contralateral lung V5Gy & $<5 \%$ & 27 & $3.74 \pm 3.56$ & 22 & 81.48 \\
\hline Contralateral lung V2Gy & - & 27 & $52.62 \pm 19.21$ & - & - \\
\hline Heart Dmean (Left breast) & $<7 G y$ & 17 & $7.25 \pm 1.82$ & 10 & 58.82 \\
\hline Heart V18Gy (Left breast) & $<5 \%$ & 17 & $2.88 \pm 2.42$ & 15 & 88.24 \\
\hline Heart V18Gy (Right breast) & $<1 \%$ & 10 & $0.33 \pm 0.55$ & 9 & 90.00 \\
\hline LAD Dmax (Left breast) & $<15 G y$ & 17 & $14.24 \pm 3.42$ & 14 & 82.35 \\
\hline LAD Dmean (Left breast) & $<8 G y$ & 17 & $7.74 \pm 3.77$ & 15 & 88.24 \\
\hline LAD Dmean (Right breast) & $<3 G y$ & 10 & $3.32 \pm 1.81$ & 8 & 80.00 \\
\hline Contralateral breast Dmean & $<3 G y$ & 27 & $2.64 \pm 0.62$ & 21 & 77.78 \\
\hline Thyroid V30 & $<25 \%$ & 27 & $11.83 \pm 14.85$ & 19 & 70.37 \\
\hline Thyroid V25 & $<50 \%$ & 27 & $19.69 \pm 21.23$ & 24 & 88.89 \\
\hline Esophagus Dmax & $<20 G y$ & 27 & $15.65 \pm 4.62$ & 19 & 70.37 \\
\hline Esophagus Dmean & $<5 G y$ & 27 & $3.69 \pm 1.58$ & 23 & 85.19 \\
\hline Spinal cord Dmax & $<30 G y$ & 27 & - & 27 & 100.00 \\
\hline Brachial plexus Dmax & $<40 G y$ & 27 & - & 27 & 100.00 \\
\hline
\end{tabular}

Table 3. Thyroid mean dose with head position and \pm SCF treatment 


\begin{tabular}{|lclll|}
\hline Group & $\mathrm{n}$ & Mean dose $\pm S D$ & $95 \% \mathrm{Cl}$ & $\mathrm{p}$ value \\
\hline Head rotation & & & & \\
Yes & 23 & $11.00 \pm 10.01$ & $6.67-15.32$ & $<0.0001$ \\
No & 4 & $22.68 \pm 1.68$ & $20.00-25.36$ & \\
SCF treatment & & & & \\
Yes & 20 & $16.95 \pm 0.35$ & $13.08-20.82$ & $<0.0001$ \\
No & 7 & $0.67 \pm 8.25$ & $0.34-0.99$ & \\
\hline
\end{tabular}

Table 4. Acute toxicities at 1 and 3 months after radiotherapy

\begin{tabular}{|c|c|c|c|c|}
\hline \multirow{2}{*}{$\begin{array}{l}\text { Toxicity } \\
\text { Physician reported }\end{array}$} & \multicolumn{2}{|l|}{1 month } & \multicolumn{2}{|l|}{3 month } \\
\hline & $\mathrm{n}(\%)$ & $\begin{array}{l}\text { Upper limit of } \\
\text { one-sided } 95 \% \mathrm{Cl}\end{array}$ & $\mathrm{n}(\%)$ & $\begin{array}{l}\text { Upper limit of } \\
\text { one-sided } 95 \% \mathrm{Cl}\end{array}$ \\
\hline Skin (grade 2) & $5(18.5)$ & 35 & $2(7.4)$ & 22 \\
\hline Hyperpigmentation (grade 2) & $1(3.7)$ & 16 & $3(11.1)$ & 27 \\
\hline Edema (grade 2) & $2(7.4)$ & 22 & $1(3.7)$ & 16 \\
\hline Induration (grade 2) & $4(14.8)$ & 31 & $5(18.5)$ & 35 \\
\hline \multicolumn{5}{|l|}{ Patient reported } \\
\hline Swelling (mild) & $2(7.4)$ & 22 & $1(3.7)$ & 16 \\
\hline Heaviness (mild) & $4(14.8)$ & 31 & $2(7.4)$ & 22 \\
\hline Pain (mild) & $8(29.6)$ & 47 & $4(14.8)$ & 31 \\
\hline \multicolumn{5}{|l|}{ Pain during swallowing } \\
\hline Mild & $1(3.7)$ & 16 & - & - \\
\hline
\end{tabular}

Table 5. Late toxicities 


\begin{tabular}{|c|c|c|c|c|c|c|}
\hline \multirow{2}{*}{$\begin{array}{l}\text { Toxicity } \\
\text { Physcian } \\
\text { reported }\end{array}$} & \multicolumn{2}{|c|}{ Baseline } & \multicolumn{2}{|c|}{ At 6 months } & \multicolumn{2}{|c|}{ At 4 years } \\
\hline & n (\%) & $\begin{array}{l}\text { Upper limit of } \\
\text { one-sided 95\% } \\
\mathrm{Cl}\end{array}$ & n (\%) & $\begin{array}{l}\text { Upper limit of } \\
\text { one-sided 95\% } \\
\mathrm{Cl}\end{array}$ & n (\%) & $\begin{array}{l}\text { Upper limit of } \\
\text { one-sided 95\% } \\
\mathrm{Cl}\end{array}$ \\
\hline \multicolumn{7}{|l|}{$\begin{array}{l}\text { Breast } \\
\text { induration }\end{array}$} \\
\hline Grade 1 & $\begin{array}{l}5 \\
(18.5)\end{array}$ & \multirow{2}{*}{$\begin{array}{l}35 \\
22\end{array}$} & \multirow{2}{*}{$\begin{array}{l}6 \\
(22.2) \\
3 \\
(11.1)\end{array}$} & \multirow{2}{*}{$\begin{array}{l}39 \\
27\end{array}$} & \multirow{2}{*}{$\begin{array}{l}4 \\
(14.8) \\
1(3.7)\end{array}$} & \multirow{2}{*}{$\begin{array}{l}31 \\
16\end{array}$} \\
\hline Grade 2 & $2(7.4)$ & & & & & \\
\hline \multicolumn{7}{|c|}{ Breast Edema } \\
\hline Grade 1 & $2(7.4)$ & 22 & $\begin{array}{l}3 \\
(11.1)\end{array}$ & 27 & $1(3.7)$ & 16 \\
\hline \multicolumn{7}{|l|}{ Fibrosis } \\
\hline Grade 1 & $1(3.7)$ & 16 & $1(3.7)$ & 16 & $1(3.7)$ & 16 \\
\hline \multicolumn{7}{|c|}{ Arm Edema } \\
\hline Grade 1 & $2(7.4)$ & 22 & $\begin{array}{l}3 \\
(11.1)\end{array}$ & 27 & $1(3.7)$ & 16 \\
\hline \multicolumn{7}{|c|}{ Patient reported } \\
\hline \multicolumn{7}{|c|}{ Breast Pain } \\
\hline Mild & $1(3.7)$ & 16 & \multirow{2}{*}{$\begin{array}{l}3 \\
(11.1) \\
2(7.4)\end{array}$} & 27 & \multirow[t]{2}{*}{$2(7.4)$} & \multirow{2}{*}{$\begin{array}{l}22 \\
-\end{array}$} \\
\hline Moderate & $1(3.7)$ & 16 & & 22 & & \\
\hline \multicolumn{7}{|l|}{$\begin{array}{l}\text { Breast } \\
\text { hardness }\end{array}$} \\
\hline Mild & $\begin{array}{l}3 \\
(11.1)\end{array}$ & \multirow{2}{*}{$\begin{array}{l}27 \\
22\end{array}$} & \multirow{2}{*}{$\begin{array}{l}3 \\
(11.1) \\
4 \\
(14.8)\end{array}$} & \multirow{2}{*}{$\begin{array}{l}27 \\
31\end{array}$} & \multirow{2}{*}{$\begin{array}{l}2(7.4) \\
1(3.7)\end{array}$} & \multirow{2}{*}{$\begin{array}{l}22 \\
16\end{array}$} \\
\hline Moderate & $2(7.4)$ & & & & & \\
\hline $\begin{array}{l}\text { Breast } \\
\text { heaviness } \\
\text { Mild }\end{array}$ & $2(7.4)$ & 22 & $\begin{array}{l}3 \\
(11.1)\end{array}$ & 27 & $2(7.4)$ & 22 \\
\hline $\begin{array}{l}\text { Breast } \\
\text { shrinkage } \\
\text { Mild }\end{array}$ & $1(3.7)$ & 16 & $2(7.4)$ & 22 & $2(7.4)$ & 22 \\
\hline
\end{tabular}


stiffness

$1(3.7) \quad 16$

$2(7.4) \quad 22$

$1(3.7) \quad 16$

Mild

Arm pain

Mild

$1(3.7) \quad 16$

$2(7.4) \quad 22$

$1(3.7) \quad 16$

Arm sweling

Mild

$1(3.7) \quad 16$

$2(7.4) \quad 22$

$1(3.7) \quad 16$

Table 6. Studies with hypofractionated SIB in breast cancer

\begin{tabular}{|c|c|c|c|c|c|c|}
\hline \multirow[b]{2}{*}{ Study } & \multirow[b]{2}{*}{$\mathrm{N}$} & \multicolumn{2}{|c|}{ Dose fractionation } & \multirow{2}{*}{$\begin{array}{l}\text { Acute Skin } \\
\text { toxicity } \\
\text { (Grade 2) }\end{array}$} & \multicolumn{2}{|l|}{ Cosmesis } \\
\hline & & $\begin{array}{l}\text { Whole } \\
\text { breast }\end{array}$ & SIB & & (Excellent/good) & $\begin{array}{l}\text { Local } \\
\text { contro }\end{array}$ \\
\hline Franco et al. ${ }^{7}$ & 82 & $45 \mathrm{~Gy} / 20 \#$ & $50 \mathrm{~Gy} / 20 \#$ & $6 \%$ & $91 \%$ & $97 \%$ \\
\hline $\begin{array}{l}\text { De Rose et } \\
\text { al. }^{8}\end{array}$ & 787 & 40.5Gy/15\# & 48Gy/15\# & $9.7 \%$ & $100 \%$ & $99 \%$ \\
\hline $\begin{array}{l}\text { Freedman et } \\
\text { al. }{ }^{9}\end{array}$ & 74 & $45 G y / 20 \#$ & $56 \mathrm{~Gy} / 20 \#$ & $23 \%$ & $77 \%$ & $97 \%$ \\
\hline $\begin{array}{l}\text { Chadha et } \\
\text { al. }{ }^{10}\end{array}$ & 74 & 40Gy/15\# & 45Gy/15\# & $4 \%$ & NR & $99 \%$ \\
\hline $\begin{array}{l}\text { Formenti et } \\
\text { al. }^{11}\end{array}$ & 91 & 40.5Gy/15\# & 48Gy/15\# & $8.1 \%$ & $96 \%$ & $98 \%$ \\
\hline Krug et al. ${ }^{43}$ & 149 & 40Gy/15\# & 48Gy/15\# & $14.7 \%$ & $91 \%$ & NR \\
\hline $\begin{array}{l}\text { Cante et } \\
\text { al. }{ }^{44,45}\end{array}$ & 465 & $45 \mathrm{~Gy} / 20 \#$ & $50 \mathrm{~Gy} / 20 \#$ & NR & $95.7 \%$ & $100 \%$ \\
\hline $\begin{array}{l}\text { Joppe et } \\
\text { al. }{ }^{46-48}\end{array}$ & 940 & $50.4 \mathrm{~Gy} / 28 \#$ & $\begin{array}{l}64.4-67.2 \\
\text { Gy/28\# }\end{array}$ & NR & $91.5 \%$ & $98.9 \%$ \\
\hline $\begin{array}{l}\text { McDonald et } \\
\text { al. }{ }^{49}\end{array}$ & 354 & $45 G y / 25 \#$ & $59.92 \mathrm{~Gy} / 28 \#$ & $43 \%$ & $96.5 \%$ & $97 \%$ \\
\hline Present study & 27 & 34Gy/10\# & 40Gy/10\# & $18.5 \%$ & $100 \%$ & $96.5 \%$ \\
\hline
\end{tabular}

Figures 

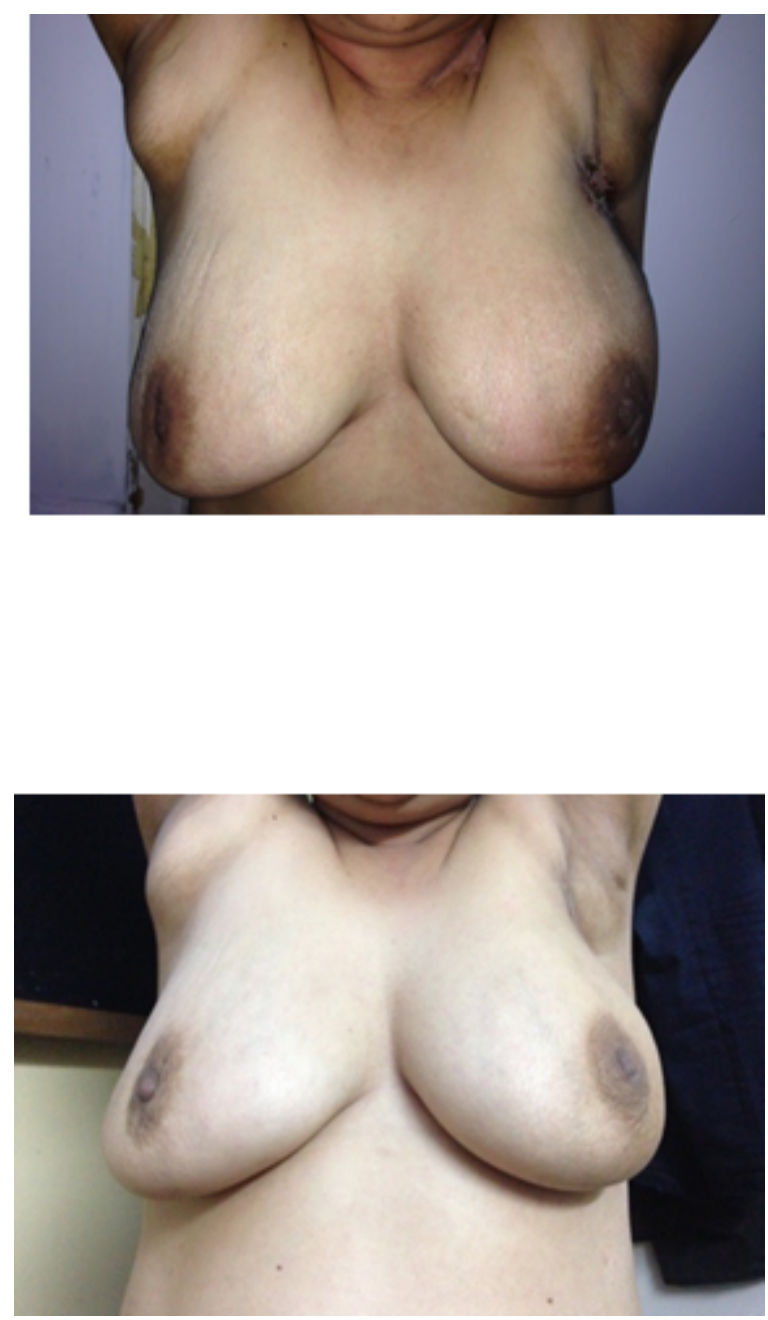

Figure 1

a. Excellent cosmesis at baseline b. Excellent cosmesis at 4 year 

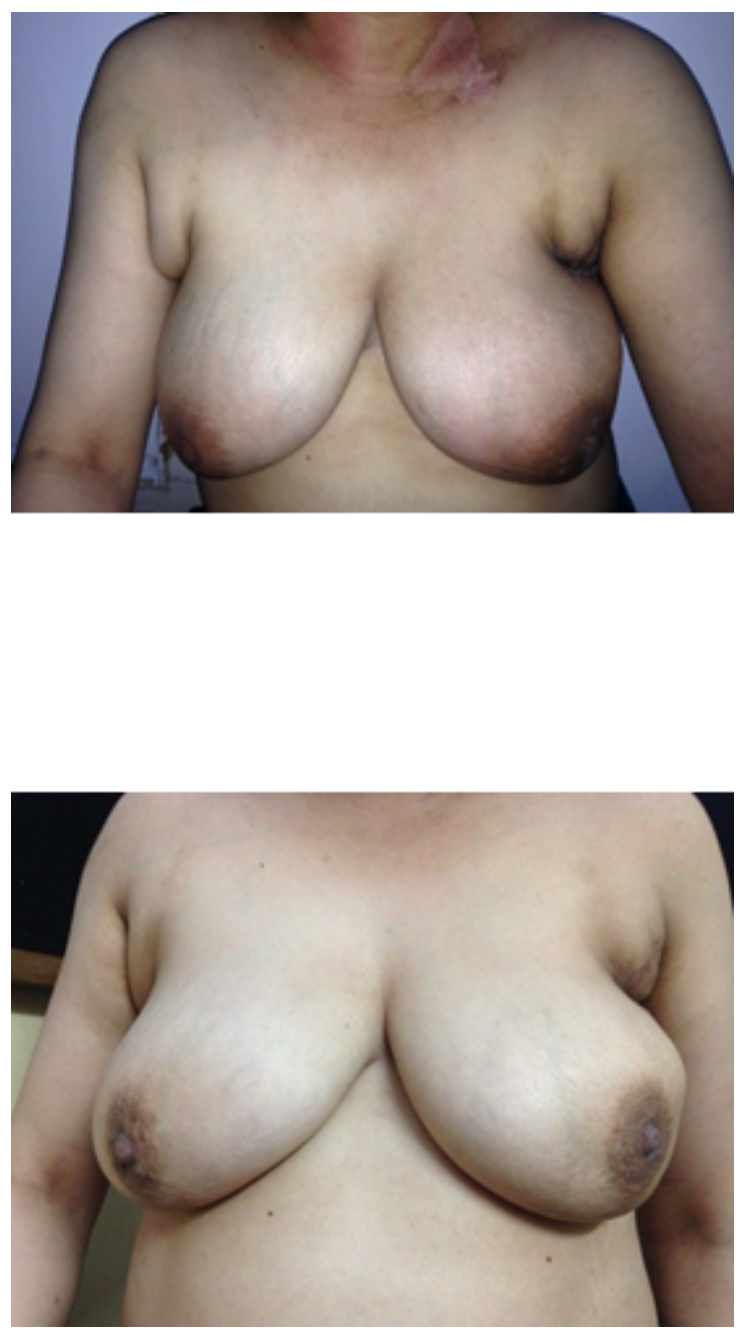

Figure 2

a. Good cosmesis at baseline b. Good cosmesis at 4 year 